\title{
Differential Therapeutic Effects of Crataegus aronia and Simvastatin on the Hepatocyte Ultrastructure in Hepatic Steatosis
}

\author{
Efectos Terapéuticos Diferenciales de Crataegus aronia y Simvastatina \\ sobre la Estructura del Hepatocito en la Esteatosis Hepática
}

Suliman Al Humayed ${ }^{1}$; Refaat A. Eid²; Abdullah S Shatoor ${ }^{1}$; Mohamed A Haidara ${ }^{3,4}$; Mohamed Samir A. Zaki²; Bahjat Al-Ani ${ }^{3}$

AL HUMAYED, S.; EID, R. A.; SHATOOR, A. S.; HAIDARA, M. A.; ZAKI, M. S. A.; AL-ANI, B. Differential therapeutic effects of Crataegus aronia and simvastatin on the hepatocyte ultrastructure in hepatic steatosis. Int. J. Morphol., 35(2):578-583, 2017.

SUMMARY: Complications of fat accumulation in liver, hepatic steatosis such as liver cirrhosis and liver failure are among the common public health problems. We sought to investigate the damage to the hepatocyte ultrastructure induced by high fat diets (HFD) and compared the therapeutic effects at the cellular level of two antioxidant and lipid lowering agents; Crataegus aronia extracts and simvastatin on hepatic steatosis. Rats were either fed with HFD (model group) or low fat diets (LFD) (control group) for 15 weeks before being sacrificed and therapeutic groups started the treatment with these agents after week 11 until the sacrifice day. Harvested liver tissues were examined using transmission electron microscopy (TEM) and liver homogenates were assayed for markers of antioxidative stress that are known to be modulated in liver injury. TEM examinations of the model group showed a profound damage to the hepatocytes compared to the control group as demonstrated by steatosis, damaged mitochondria and vaculated cytoplasm, disrupted rough and smooth endoplasmic reticulum and nuclear membrane, dilated intercellular space between hepatocytes, and alterations in lysosomes. In addition, HFD ameliorated the anti-oxidant glutathione (GSH) and augmented the oxidative stress TBARS biomarkers. Both Crataegus aronia and simvastatin significantly reduced lipids and TBARS, and treated damage to hepatic cells, but hepatocyte structures were differentially responded to these agents. However, only Crataegus aronia induced GSH ( $\mathrm{p}=0.001)$. We conclude that HFD-induced hepatic steatosis caused a substantial damage to the hepatocyte's ultrastructures, and Crataegus aronia and simvastatin treatments differentially reversed hepatic injuries.

KEY WORDS: Hepatic steatosis; Mitochondrial dysfunction; NAFLD; Crataegus aronia; Simvastatin.

\section{INTRODUCTION}

Metabolic syndrome or insulin resistance syndrome is a cluster of abnormalities including insulin resistance, inflammation, oxidative stress, hypertension and dyslipidaemia that results from increasing the prevalence of obesity (Eckel et al., 2005) . Non alcoholic fatty liver disease (NAFLD) is the hepatic component of metabolic syndrome (Paschos \& Paletas, 2009) that affects liver function due to fat over-accumulation (hepatic steatosis) caused by dysfunction of fat metabolism in the liver (Benlhabib et al., 2004), which is histologically comparable to liver disease caused by alcohol abuse (Sakhuja, 2014). It has a wide spectrum of fatty liver changes ranging from hepatic steatosis to nonalcoholic steatohepatitis (NASH), which can progress to liver fibrosis and cirrhosis in the absence of al- cohol consumption ( Chalasani et al., 2012). NAFLD is becoming the most common cause of liver disease in Western countries (de Alwis \& Day, 2008), and is associated with significant liver related morbidity and mortality (Byrne \& Targher, 2015).

Treatment strategies for NAFLD aim to improve insulin sensitivity, decrease hepatic accumulation of fat, modify metabolic risk factors and protect the liver from oxidative stress (Chalasani et al., 2012). Furthermore, certain approaches such as weight loss, taking insulin sensitizing drugs and vitamin E showed some benefits (Sanyal et al., 2010). However, the precise mechanisms of NAFLD are still not fully understood and there is no specific medicine to

\footnotetext{
${ }^{1}$ Departments of Medicine, College of Medicine, King Khalid University, Abha 61421, Saudi Arabia.

${ }^{2}$ Pathology and Anatomy, College of Medicine, King Khalid University, Abha 61421, Saudi Arabia.

${ }^{3}$ Physiology, College of Medicine, King Khalid University, Abha 61421, Saudi Arabia.

${ }^{4}$ Department of Physiology, Kasr al-Aini Faculty of Medicine, Cairo University, Cairo, Egypt.
} 
cure the disease, which left patients with only one option of effective treatment, liver transplant, if progress of the disease leads to a liver failure (Said, 2013).

The hawthorn plant (Crataegus species) is widely used worldwide in herbal medicine to treat a broad range of diseases such as heart diseases (Tassell et al., 2010), atherosclerosis (Quettier-Deleu et al., 2003), and antiplatelet function (Shatoor et al., 2012). We recently reported protective and therapeutic effects of Crataegus aronia extracts on NAFLD in animal models (Al Humayed 2016), and here we investigated the ultrastructural changes in hepatocytes upon induction of hepatic steatosis in rats fed on a high fat diet using transmission electron microscopy (TEM) and compared the effects of Crataegus aronia and simvastatin on restoring the architecture of liver cells distorted by the disease. In addition, we monitored the levels of anti-oxidative and stress biomarkers in liver tissue homogenates obtained from these animals.

\section{MATERIAL AND METHOD}

Animals. Wistar male rats weighing 180- 200 gm were used for the experiments with the approval of Ethical Committee of the college of medicine, King Khalid University, Abha, Saudi Arabia. The animals were obtained from the animal house of the College of Medicine of King Khalid University where they were fed with standard rat's pellets and allowed free access to water. They were housed at a controlled ambient temperature of $25 \pm 2{ }^{\circ} \mathrm{C}$ and $50 \pm 10 \%$ relative humidity, with 12-h light/12-h dark cycles. Experiments were performed according to the Guide for the Care and Use of Laboratory Animals published by the US National Institutes of Health (NIH publication No. 85-23, revised 1996).

Preparation of the Crataegus aronia extract. Crataegus aronia extract was prepared as previously reported by our group (Al Humayed 2016; Shatoor et al., 2012).

Experimental design. After a one week of adaptation period, the rats were randomly divided into four groups $(n=6)$ and were classified as Control group (LFD):rats were fed with standard laboratory chow for 15 weeks; HFD group: rats were fed HFD for 15 weeks to induce NAFLD; HFD + aronia group: rats were fed HFD for 11 weeks and then received Crataegus aronia (200 $\mathrm{mg} / \mathrm{kg}$ body weight/day) during the last 4weeks; HFD + simvastatin: rats were fed with HFD for 11 weeks and then received simvastatin $(4 \mathrm{mg} / \mathrm{kg}$ of body weight/day) during the last 4 weeks of the experiment ( $\mathrm{Al}$ Humayed 2016). At the end of experiment, rats were sacrificed and blood and liver tissues were collected.
Transmission Electron Microscopy (TEM). The small pieces of the liver were removed and immediately fixed in 2.5 $\%$ glutaraldehyde for 24 hours and prepared for TEM as we previously mentioned (Eid et al., 2012). Three to five random micrographs for each thin section were examined and photographed using JEM-1011-JEOL transmission electron microscope, Japan, at $80 \mathrm{Kv}$.

Determination of reduced glutathione (GSH) and thiobarbituric acid reactive substances (TBARS) in liver homogenate. Reduced glutathione (GSH) levels in the tissue homogenates were measured using commercials kits from Randox Laboratories Ltd. (UK) and TBARS levels in liver tissues were analyzed as recommended by the manufacturer.

Blood lipid analysis. The concentrations of serum total cholesterol, triglyceride, and low density lipoprotein were measured using the corresponding commercial enzyme kits (HUMAN Diagnostics, Wiesbaden, Germany).

Statistical analysis. Graphing and comparison between the groups were analyzed by one way ANOVA test and significant comparisons were determined by Tukey's post-hoc test using GraphPad Prism software (version 6). All data are expressed as mean $\pm \mathrm{SD}$. Values of $\mathrm{P}<0.05$ were considered to be statistically significant.

\section{RESULTS}

Crataegus aronia and simvastatin differentially modulate hepatic cells ultrastructure in HFD-induced hepatic steatosis. To test the hypothesis that Crataegus aronia and simvastatin can modulate hepatocytes ultrastructure in hepatic steatosis, we induced the disease in rats fed on HFD for 11 weeks and we then carried on feeding the HFD rats for an additional 4 weeks in the presence and absence of these agents separately before sacrifice. Liver tissues were prepared from the four rat groups and visualized using TEM. The control group, LFD showed intact hepatocellular architecture and hepatocyte ultrastructure like normal intercellular spaces between hepatocytes, normal mitochondria (round or elongated) and rough endoplasmic reticuli (RER), and absence of lipid droplets (Fig. 1A). Whereas, liver sections of the HFD group (Fig. 1B - 1D) showed degenerated hepatocytes, with different sized lipid droplets (steatosis) (Fig. 1B and 1C), cytoplasmic vacuoles (Fig. 1B - 1D) and an increased number of lysosomes (Fig. 1B and 1D). In addition, damaged and vacuolated endoplasmic reticului (Fig. 1B and 1D), swollen and pleomorphic mitochondria (Fig. 1B - 1D), distorted intercellular spaces between degenerated hepatocytes, and irregular nuclear membranes (Fig. 1D) are also shown. 

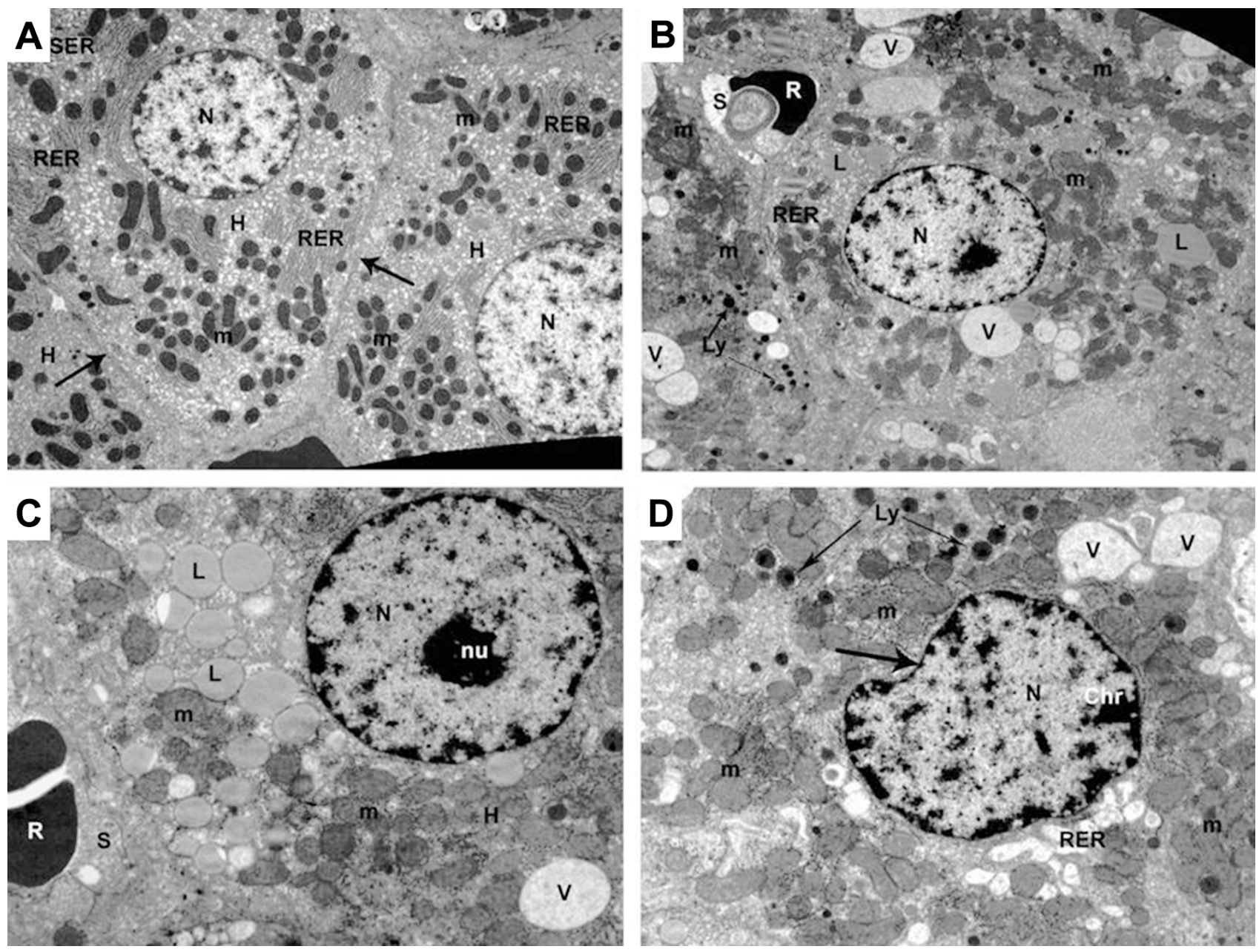

Fig. 1. Hepatic steatosis induced in rats fed on a HFD caused damages to the hepatocytes ultrastructure. TEM images (x5000 and $\mathrm{x} 10000$ ) of harvested tissues obtained after 15 weeks from the liver of the control (LFD) and model (HFD) groups of rats are depicted. (A). Control group (x5000). (B). HFD group (x5000). (C). HFD group (x10000). (D). HFD group (x10000). Note that arrows in A point to intercellular spaces between hepatocytes; and the thick arrow in D points to the irregular nuclear membrane. Abbreviations: H, hepatocyte; N, nucleous; L, lipid droplets; $\mathrm{m}$, mitochondria; V, vacuoles; RER, rough endoplasmic reticulum; SER, smooth endoplasmic reticulum; Chr, chromatin masses; Lys, lysosomes; S, blood sinusoid; R, erythrocyte; nu, nucleolus.

Treatment of NAFLD rats with either Cratageus aronia (Fig. 2A) or simvastatin (Fig. 2B) substantially restored the hepatocellular architecture and hepatocytes ultrastructure but with differential therapies between these two agents. For example, simvastatin was more effective than Cratageus aronia in treating the lipid droplets (healing of steatosis), and endoplasmic reticulum; whereas, Cratageus aronia was more effective than simvastatin to treat mitochondria (Fig. $2 \mathrm{~A}$ and $2 \mathrm{~B}$ ). However, both Cratageus aronia and simvastatin were comparable in healing the intercellular spaces between hepatocytes, lysosomes and vacuoles (Fig. 2A and 2B).

Crataegus aronia and simvastatin differentially modulate biomarkers of oxidative stress and lipids in HFD-induced hepatic steatosis. To investigate the potential relative therapeutic effects of Crataegus aronia and simvastatin on upregulation the antioxidant GSH and suppression the oxidative stress TBARS and lipidemia, we measured reduced GSH and TBARS biomarkers in liver homogenates and lipid fractions (cholesterol, triaceylglycerol, and low density lipoprotein (LDL)) in the blood of rats sacrificed after 15 weeks (Table I). Compared to LFD group, our results showed that induction of hepatic steatosis (HFD group) significantly inhibited GSH (73.46 \pm 5.22 in LFD group versus $40.60 \pm 6.18$ in HFD model group; $\mathrm{p}<0.0001$ ) and augmented TBARS, cholesterol, triacylglycerol, and LDL $(\mathrm{p}<0.0001)$. Crataegus aronia significantly inhibited TBARS $(\mathrm{p}=0.001)$, cholesterol, triacylglycerol, and LDL $(\mathrm{p}<0.001)$. 

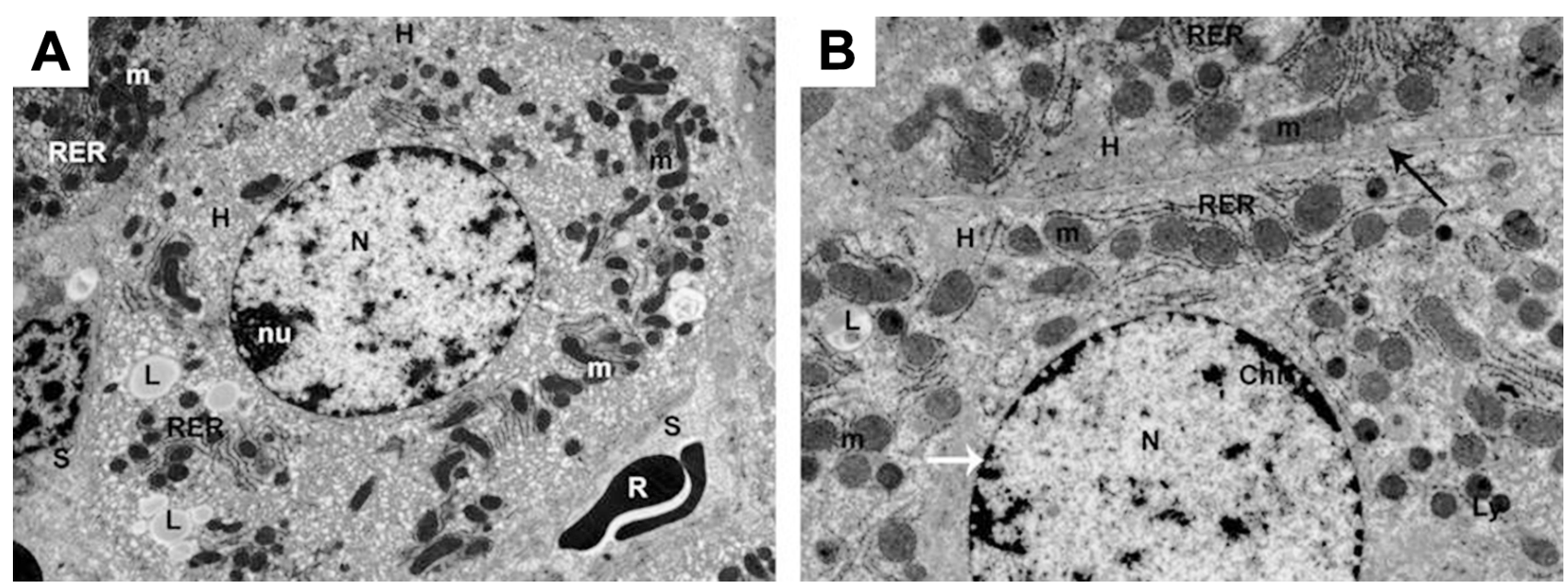

Fig. 2. Effects of Crataegus aronia and simvastatin treatments on the healing of hepatocytes ultrastructure in hepatic steatosis induced liver injury. TEM images (x5000) of harvested tissues obtained after 15 weeks from the liver in rats treated with aronia (A) and simvastatin (B). Note that black and white arrows in image B point to normal intercellular space between hepatocytes and intact nuclear membrane, respectively. Abbreviations: H, hepatocyte; N, nucleous; L, lipid droplets; m, mitochondria; RER, rough endoplasmic reticulum; Chr, chromatin masses; Ly, lysosome; S, blood sinusoid; R, erythrocyte; nu, nucleolus.

The degree of inhibition by Crataegus aronia was comparable to simvastatin for cholesterol and triacylglycerol, but Crataegus aronia was more effective in inhibiting LDL and TBARS (Table I). On the other hand, Crataegus aronia significantly augmented GSH (54.40 \pm 3.72 in HFD+aronia group versus 40.60 \pm 6.18 in HFD group; $\mathrm{p}=0.001$ ) but not simvastatin (45.60 \pm 3.85 in HFD+Sim group versus $40.60 \pm 6.18$ in HFD group; $\mathrm{p}=0.39$ ) (Table I).

Table I. Tissue levels of the antioxidant (GSH) and free radicals (TBARS) in liver homogenates and blood lipids for all the experimental groups.

\begin{tabular}{|c|c|c|c|c|c|}
\hline Animal groups & $\begin{array}{l}\text { Glutathione (GSH) } \\
\text { levels (mg/g tissue) }\end{array}$ & $\begin{array}{c}\text { TBARS (mM/100g } \\
\text { tissue) }\end{array}$ & $\begin{array}{l}\text { Cholesterol } \\
(\mathrm{mg} / \mathrm{dL})\end{array}$ & $\begin{array}{c}\text { Triacylglycerol } \\
(\mathrm{mg} / \mathrm{dL})\end{array}$ & LDL (mg/dL) \\
\hline LFD & $73.46 \pm 5.22$ & $0.50 \pm 0.11$ & $63.32 \pm 4.85$ & $42.23 \pm 6.18$ & $31.54 \pm 1.61$ \\
\hline HFD & $40.60 \pm 6.18^{*}$ & $0.92 \pm 0.11^{*}$ & $169.30 \pm 13.66^{*}$ & $271.50 \pm 41.99^{*}$ & $93.57 \pm 4.59^{*}$ \\
\hline HFD + aronia & $54.40 \pm 3.72^{*}-$ & $0.63 \pm 0.12-$ & $106.30 \pm 3.22^{*}-$ & $114.90 \pm 8.98 *$ & $61.95 \pm 4.71 *$ \\
\hline HFD + SIM & $45.60 \pm 3.85^{* \$}$ & $0.74 \pm 0.04^{*-}$ & $114.80 \pm 4.22^{*}-$ & $129.30 \pm 4.65^{*}-$ & $74.45 \pm 3.34 * \$$ \\
\hline
\end{tabular}

Values are expressed as Mean \pm SD for 6 rats in each group. Analysis by one way ANOVA and Tukeys t-test. Values were considered significantly different at $\mathrm{P}<0.05$. *: Significant in comparison LFD group, 1:Significant in comparison to HFD, \$: versus HFD plus aronia.

\section{DISCUSSION}

The main objectives of our study were to investigate the impact of hepatic steatosis induced by HFD on the hepatocyte's ultrastructure and to compare the therapeutic effects of two antioxidant and lipid lowering agents; the herbal medicine Crataegus aronia and simvastatin drug on restoring the normal hepatocellular architecture. The principal findings in our study were (i) HFD in addition to causing accumulation of lipid droplets inside the hepatocytes, damaged the ultrastructure of these hepatic cells; (ii) the tested agents, Crataegus aronia and simvastatin differentially treated hepatocyte damage that incurred upon feeding rats with HFD; and (iii) Crataegus aronia but not simvastatin augmented reduced GSH levels in liver tissue homogenates. These conclusions are supported by the transmission electron microscopy (Figs. 1 and 2) and ELISA (Table I) data indicating that HFD induced NAFLD in rats caused steatosis, the appearance of intracytoplasmic vacuoles, and an increase in number of lysosomes in hepatocytes. In addition, HFD caused swelling and damage to the mitochondria, RER, dilated intercellular spaces between hepatocytes and irregular nuclear membrane (Fig. 1). Degenerated hepatocytes were significantly treated by Crataegus aronia and simvastatin with differential effects towards the hepatocytes 
ultrastructure (Fig. 2). The lipid lowering (Garcia et al., 2016), antioxidant (Eger et al., 2016) and antiinflammatory (Al-Ani, 2013) effects of simvastatin and the presence of polyphenolic antioxidants, flavonoids, oligomeric flavonoids (proanthocyanidins), and catechins (Kim et al., 2000) in the hawthorn plant could be the reason for the observed substantial treating effects of Crataegus aronia and simvastatin and a better architecture of liver cells.

Hyperlipidaemia and oxidative stress are known to be involved in the pathology of liver disease (Le Lay et al., 2014). Liver sections obtained from mice fed on HFD for 21 days showed by transmission electron microscopy the presence of atypical mitochondria with different volumes (Kahle et al., 2014). Furthermore, NAFLD can lead to mitochondrial dysfunction and apoptosis and fibrosis of hepatocytes (Williams et al., 2015, Garcia-Ruiz $\&$ Fernandez-Checa, 2006). These reports are in agreement with our findings on HFD-induced NAFLD in rats that showed degenerated hepatocytes including atypical mitochondria (Fig. 1B-1D).

Simvastatin was previously used to treat liver injury induced by LPS in rats (La Mura et al., 2013) and also treated the advanced type of NAFLD, NASH, in Wistar rats fed on a HFD for 24 weeks (Wang et al., 2013). These reports are in partial agreement with our results that showed effective but not complete healing of hepatocytes ultrastructure with simvastatin (Fig. 2B). The discrepancies could be attributed to the assessment methods used; basic histological staining in theirs compared to transmission electron microscopy methods in ours. Furthermore, simvastatin was also found to reduce the levels of blood cholesterol and triacylglycerol (Wang et al., 2013), and liver TBARS (Ozansoy 2001), however it failed to increase the antioxidants GSH, glutathione-S-transferase, and glutathione peroxidase in liver tissue homogenates obtained from rats fed on HFD and from aged rats (Abbas \& Sakr, 2013, Helmy, 2012). These findings are in total agreement with our data reported here on the effect of simvastatin that showed a reduction in blood lipids, TBARS, but no significant GSH increase with simvastatin (Table I).

Another species of Crataegus genus, oxyacantha was reported to have cardioprotective effect and antioxidant activity by inhibiting lipid peroxidation (TBARS) and augmenting enzymatic and non-enzymatic antioxidants in experimentally induced myocardial infarction in rats (Jayalakshmi \& Niranjali Devaraj, 2004). In addition, extracts of Crataegus aronia $(400 \mathrm{mg} / \mathrm{kg})$ decreased total cholesterol and LDL in rats (Al-Hallaq et al., 2012). In this study, Crataegus aronia $(200 \mathrm{mg} / \mathrm{kg}$ ) was able to significantly increase the antioxidant GSH, inhibits TBARS and lipid fractions, and substantially treats degenerated hepatocytes, which complement these published studies.

In summary, we believe our data demonstrates that HFD-induced hepatic steatosis in rats damaged the ultrastrucutre of hepatocytes possibly via augmentation of lipids and oxidative stress biomarkers and inhibition of the antioxidant biomarker, the reduced GSH. In addition, Crataegus aronia and simvastatin differentially treat degenerate hepatocytes.

ACKNOWLEDGEMENTS: The authors would like to express their gratitude to King Khalid University, Saudi Arabia for providing administrative and technical support. We also would like to thank Mrs. Rochelle Thody from Tom Baker Cancer Centre, Calgary, Alberta, Canada T2N 4N2 for proofreading the manuscript.

AL HUMAYED, S.; EID, R. A.; SHATOOR, A. S.; HAIDARA, M. A.; ZAKI, M. S. A. \& AL-ANI, B. Efectos terapéuticos diferenciales de Crataegus aronia y simvastatina sobre la estructura del hepatocito en la esteatosis hepática. Int. J. Morphol., 35(2):578-583, 2017.

RESUMEN: Las complicaciones de la acumulación de grasa en el hígado, la esteatosis hepática como la cirrosis hepática y la insuficiencia hepática se encuentran entre los problemas comunes de salud pública. Se intentó investigar el daño a la ultraestructura de los hepatocitos inducido por la dieta alta en grasas (DAG) y se compararon los efectos terapéuticos a nivel celular de dos antioxidantes y agentes hipolipemiantes; Extracto de Crataegus aronia y simvastatina sobre esteatosis hepática. Las ratas fueron alimentadas con DAG (grupo modelo) o dieta baja en grasa (DBG) (grupo control) durante 15 semanas antes de sacrificarse y los grupos terapéuticos comenzaron el tratamiento con estos agentes después de la semana 11 hasta el día del sacrificio. Se examinaron los tejidos hepáticos usando microscopía electrónica de transmisión (MET) y se analizaron homogeneizados de hígado para marcadores de estrés anti-oxidativo, que se sabe están modulados en la lesión hepática. Los exámenes MET del grupo DAG mostraron un grave daño de los hepatocitos en comparación con el grupo control, demostrado por esteatosis, daño mitocondrial y citoplasma vacío, retículo endoplásmico rugoso y liso y membrana nuclear, el espacio intercelular dilatado entre hepatocitos y alteraciones en los lisosomas. Además, DAG mejoró el anti-oxidante glutatión (GSH) y aumentó el estrés oxidativo TBARS biomarcadores. Tanto Crataegus aronia como simvastatina redujeron significativamente los lípidos y TBARS, trataron el daño a las células hepáticas, pero las estructuras de hepatocitos respondieron diferencialmente a estos agentes. Sin embargo, sólo Crataegus aronia indujo GSH (p=0,001). Concluimos que la esteatosis hepática inducida por HFD causó un daño sustancial a la ultraestructura del hepatocito y los tratamientos de Crataegus aronia y simvastatina diferenciaron las lesiones hepáticas.

PALABRAS CLAVE: Estteatosis hepática; Disfunción mitocondrial; NAFLD; Crataegus aronia; Simvastatina. 


\section{REFERENCES}

Abbas, A. M. \& Sakr, H. F. Simvastatin and vitamin E effects on cardiac and hepatic oxidative stress in rats fed on high fat diet. J. Physiol. Biochem., 69(4):737-50, 2013.

Al Humayed, S. Protective and therapeutic effects of Crataegus aronia in non-alcoholic fatty liver disease. Arch. Physiol. Biochem., 123(1):2330, 2017.

Al-Ani, B. Simvastatin inhibits neutrophil degranulation induced by antineutrophil cytoplasm auto-antibodies and $\mathrm{N}$-formyl-methionineleucine-phenylalanine (fMLP) peptide. Saudi Med. J., 34(5):477-83, 2013.

Al-Hallaq, E. K.; Afifi, F. U. \& Abdalla, S. S. Evaluation of the hypocholesterolemic effect and phytochemical screening of the hydroethanolic extract of Crataegus aronia from Jordan. Nat. Prod. Commun., 7(1):35-8, 2012

Benlhabib, E.; Baker, J. I.; Keyler, D. E. \& Singh, A. K. Effects of purified puerarin on voluntary alcohol intake and alcohol withdrawal symptoms in $\mathrm{P}$ rats receiving free access to water and alcohol. J. Med. Food, 7(2): 180-6, 2004.

Byrne, C. D. \& Targher, G. NAFLD: a multisystem disease. J. Hepatol., 62(1 Suppl.):S47-64, 2015.

Chalasani, N.; Younossi, Z.; Lavine, J. E.; Diehl, A. M.; Brunt, E. M.; Cusi, K.; Charlton, M. \& Sanyal, A. J. The diagnosis and management of non-alcoholic fatty liver disease: practice Guideline by the American Association for the Study of Liver Diseases, American College of Gastroenterology, and the American Gastroenterological Association. Hepatology, 55(6):2005-23, 2012.

de Alwis, N. M. \& Day, C. P. Non-alcoholic fatty liver disease: the mist gradually clears. J. Hepatol., 48 Suppl. 1:S104-12, 2008.

Eckel, R. H.; Grundy, S. M. \& Zimmet, P. Z. The metabolic syndrome. Lancet, 365(9468):1415-28, 2005.

Eger, G. A.; Ferreira, V. V.; Batista, C. R.; Bonde, H.; de Lima, D. D.; Wyse, A. T.; da Cruz, J. N.; Rodrigues, A. F.; Magro, D. D. \& da Cruz, J. G. Antioxidant effect of simvastatin throught oxidative imbalance caused by lisdexamfetamine dimesylate. An. Acad. Bras. Cienc., 88(1):335-48, 2016

Eid, R. A.; Radad, K. \& Al-Shraim, M. Ultrastructural changes of smooth muscles in varicocele veins. Ultrastruct. Pathol., 36(4):201-6, 2012.

Garcia-Ruiz, C. \& Fernandez-Checa, J. C. Mitochondrial glutathione: hepatocellular survival-death switch. J. Gastroenterol. Hepatol., 21 Suppl. 3:S3-6, 2006

Garcia, M. M.; Varela, C. G.; Silva, P. F.; Lima, P. R.; Góes, P. M.; Rodrigues, M. G.; Silva, M. de L.; Ladeia, A. M.; Guimarães, A. C. \& Correia, L. C. Endothelial effect of statin therapy at a high dose versus low dose associated with ezetimibe. Arq. Bras. Cardiol., 106(4):27988, 2016.

Helmy, M. M. Potential hepato-protective effect of a-tocopherol or simvastatin in aged rats. Pharmacol. Rep., 64(3):698-705, 2012.

Jayalakshmi, R. \& Niranjali Devaraj, S. Cardioprotective effect of tincture of Crataegus on isoproterenol-induced myocardial infarction in rats. $J$. Pharm. Pharmacol., 56(7):921-6, 2004.

Kahle, M.; Schäfer, A.; Seelig, A.; Schultheiß, J.; Wu, M.; Aichler, M.; Leonhardt, J.; Rathkolb, B.; Rozman, J.; Sarioglu, H.; Hauck, S. M.; Ueffing, M.; Wolf, E.; Kastenmueller, G.; Adamski, J.; Walch, A.; Hrabé de Angelis, M. \& Neschen, S. High fat diet-induced modifications in membrane lipid and mitochondrial-membrane protein signatures precede the development of hepatic insulin resistance in mice. Mol. Metab., 4(1):39-50, 2014.

Kim, S. H.; Kang, K. W.; Kim, K. W. \& Kim, N. D. Procyanidins in crataegus extract evoke endothelium-dependent vasorelaxation in rat

aorta. Life Sci., 67(2):121-31, 2000.

La Mura, V.; Pasarín, M.; Meireles, C. Z.; Miquel, R., RodríguezVilarrupla, A.; Hide, D.; Gracia-Sancho, J.; García-Pagán, J. C.; Bosch, J. \& Abraldes, J. G. Effects of simvastatin administration on rodents with lipopolysaccharide-induced liver microvascular dysfunction. Hepatology, 57(3):1172-81, 2013.

Le Lay, S.; Simard, G.; Martinez, M. C. \& Andriantsitohaina, R. Oxidative stress and metabolic pathologies: from an adipocentric point of view. Oxid. Med. Cell Longev., 2014:908539, 2014.

Ozansoy, G.; Akin, B.; Aktan, F. \& Karasu, C. Short-term gemfibrozil treatment reverses lipid profile and peroxidation but does not alter blood glucose and tissue antioxidant enzymes in chronically diabetic rats. Mol. Cell. Biochem., 216(1-2):59-63, 2001.

Paschos, P. \& Paletas, K. Non alcoholic fatty liver disease and metabolic syndrome. Hippokratia, 13(1):9-19, 2009.

Quettier-Deleu, C.; Voiselle, G.; Fruchart, J. C.; Duriez, P.; Teissier, E.; Bailleul, F.; Vasseur, J. \& Trotin, F. Hawthorn extracts inhibit LDL oxidation. Pharmazie, 58(8):577-81, 2003.

Said, A. Non-alcoholic fatty liver disease and liver transplantation: outcomes and advances. World. J. Gastroenterol., 19(48):9146-55, 2013.

Sakhuja, P. Pathology of alcoholic liver disease, can it be differentiated from nonalcoholic steatohepatitis? World. J. Gastroenterol., 20(44):16474-9, 2014.

Sanyal, A. J.; Chalasani, N.; Kowdley, K. V.; McCullough, A.; Diehl, A. M.; Bass, N. M., Neuschwander-Tetri, B. A.; Lavine, J. E.; Tonascia, J.; Unalp, A.; Van Natta, M.; Clark, J.; Brunt, E. M.; Kleiner, D. E.; Hoofnagle, J. H.; Robuck, P. R. \& NASH CRN. Pioglitazone, vitamin E, or placebo for nonalcoholic steatohepatitis. N. Engl. J. Med., 362(18):1675-85, 2010.

Shatoor, A. S.; Soliman, H.; Al-Hashem, F.; Gamal, B. E.; Othman, A. \& El-Menshawy N. Effect of Hawthorn (Crataegus aronia syn. Azarolus (L)) on platelet function in albino Wistar rats. Thromb. Res., 130(1):7580, 2012.

Tassell, M. C.; Kingston, R.; Gilroy, D.; Lehane, M. \& Furey, A. Hawthorn (Crataegus spp.) in the treatment of cardiovascular disease. Pharmacogn. Rev., 4(7):32-41, 2010.

Wang, W.; Zhao, C.; Zhou, J.; Zhen, Z.; Wang, Y. \& Shen, C. Simvastatin ameliorates liver fibrosis via mediating nitric oxide synthase in rats with non-alcoholic steatohepatitis-related liver fibrosis. PLoS One, 8(10):e76538, 2013.

Williams, K. H.; Vieira De Ribeiro, A. J.; Prakoso, E.; Veillard, A. S.; Shackel, N. A.; Brooks, B.; Bu, Y.; Cavanagh, E.; Raleigh, J.; McLennan, S. V.; McCaughan, G. W.; Keane, F. M.; Zekry, A.; Gorrell, M. D. \& Twigg, S. M. Circulating dipeptidyl peptidase-4 activity correlates with measures of hepatocyte apoptosis and fibrosis in nonalcoholic fatty liver disease in type 2 diabetes mellitus and obesity: A dual cohort cross-sectional study. J. Diabetes, 7(6):809-19, 2015.

\section{Corresponding author: \\ Prof. Bahjat Al-Ani \\ Department of Physiology \\ College of Medicine \\ King Khalid University \\ Abha 61421 \\ SAUDI ARABIA}

Received: 10-11-2016

Accepted: 16-01-2017

E-mail: bahjat_alani@yahoo.com 